\title{
Gender-specific psychological and social impact of COVID-19 in Pakistan
}

\author{
Fauziah Rabbani, Hyder Ali Khan, Suneel Piryani, Areeba Raza Khan and Fahad Abid
}

\section{Background}

COVID-19 has rapidly spread across the world. Women may be especially vulnerable to depression and anxiety as a result of the pandemic.

\section{Aims}

This study attempted to assess how gender affects risk perceptions, anxiety levels and behavioural responses to the COVID-19 pandemic in Pakistan, to recommend gender-responsive health policies.

\section{Methods}

A cross-sectional online survey was conducted. Participants were asked to complete a sociodemographic data form, the Hospital Anxiety and Depression Scale, and questions on their risk perceptions, preventive behaviour and information exposure. Multiple logistic regression analysis was used to assess the effects of factors such as age, gender and household income on anxiety levels.

\section{Results}

Of the 1391 respondents, 478 were women and 913 were men. Women considered their chances of survival to be relatively lower than men (59\% v. 73\%). They were also more anxious (62\% v. 50\%) and more likely to adopt precautionary behaviour, such as avoiding going to the hospital (78\% v. $71 \%)$, not going to work
(72\% v. $57 \%$ ) and using disinfectants (93\% v. $86 \%)$. Men were more likely to trust friends, family and social media as reliable sources of COVID-19 information, whereas women were more likely to trust doctors.

\section{Conclusions}

Women experience a disproportionate burden of the psychological and social impact of the pandemic compared with men. Involving doctors in healthcare communication targeting women might prove effective. Social media and radio programmes may be effective in disseminating COVID-19-related information to men.

\section{Keywords}

Risk perception; anxiety disorders; depressive disorders; COVID-19; low- and middle-income countries.

\section{Copyright and usage}

(C) The Author(s), 2021. Published by Cambridge University Press on behalf of the Royal College of Psychiatrists. This is an Open Access article, distributed under the terms of the Creative Commons Attribution licence (https://creativecommons.org/ licenses/by/4.0/), which permits unrestricted re-use, distribution, and reproduction in any medium, provided the original work is properly cited.
The COVID-19 virus was first detected in December 2019 in Wuhan, China. ${ }^{1}$ On 11 March 2020, the World Health Organization declared the disease a global pandemic. Since its emergence, there are more than 15.2 million confirmed global cases of the virus, with the number of deaths exceeding 623000 as of 23 July 2020. In the initial stages of the outbreak, most cases of COVID-19 that were exported internationally had a history of prior travel to Wuhan. ${ }^{2}$ Despite its close geographic proximity with China and Iran, the first two cases of COVID-19 in Pakistan were reported on 26 February 2020. ${ }^{3}$ To curb the spread of the virus, provincial governments in Pakistan initiated partial followed by complete lockdowns in their respective administrative territories. These measures, however, were taken in phases, with educational institutions across the country closing on 13 March 2020, in response to the pandemic. ${ }^{4}$ As of 23 July 2020, Pakistan has over 260000 confirmed cases of COVID-19, and approximately 5700 deaths. ${ }^{1}$ One year on, Pakistan has experienced four waves of the pandemic, with a total number of 1.2 million cases and 26000 deaths. ${ }^{5}$

Exposure to a traumatic event, such as a global health crisis, is associated with an increased incidence of anxiety and depression. ${ }^{6}$ Moreover, the stigma and isolation associated with infectious diseases could generate anxiety. ${ }^{7}$ A study conducted on a sample of severe acute respiratory syndrome (SARS) survivors in Hong Kong revealed increased levels of psychological distress and anxiety, not only during the epidemic but also 1 year following the outbreak. ${ }^{8}$ Another study concluded that SARS had long-term psychiatric effects on survivors, with post-traumatic stress disorder (PTSD) and depressive disorders being the most prevalent conditions recorded. ${ }^{9}$ Moreover, a survey conducted in the USA during the H1N1 pandemic, with 7236 participants, suggests an increase in the prevalence of anxiety. ${ }^{10}$

The COVID-19 pandemic is expected to affect women's health and increase their short- and long-term needs for livelihood support and health. ${ }^{11}$ A study conducted in the heavily affected areas around Wuhan highlighted an increase of 7\% in the prevalence of post-traumatic stress symptoms (PTSS), and women had significantly higher levels of PTSS than men. ${ }^{12}$ During the SARS epidemic, people with higher levels of anxiety were frequently found to adopt precautionary behaviour. ${ }^{13}$ In keeping with this, a study conducted in the UK found that women practiced precautionary behaviour, such as hand washing and disinfecting surfaces, more often than men. ${ }^{14}$

Female responses to stress and trauma may be contributing factors toward anxiety. Studies also indicate that gendered responses to trauma contribute to the greater onset of depression and PTSD in women. ${ }^{15}$ Evidence attributes this to women believing that worry is uncontrollable, and may cause anxious thoughts. ${ }^{16}$ How young boys and girls are socialised into their gender roles has an impact on these perceptions. A review discussed how mothers are more likely to converse about their emotional condition with their daughters, compared with their sons. ${ }^{17}$ Further, young boys are conditioned to exercise problem-solving skills for managing their emotions, girls are traditionally granted less autonomy. This increases their dependency on others and reduces their capability to effectively cope with anxious thoughts. ${ }^{17}$ Studies from the Eastern Mediterranean region further highlight this, suggesting that this ineffective coping may result in a higher suicide rate among women. ${ }^{18}$ Indeed, in 2020 , there were significantly higher female 
hospital admissions in Malta compared with 2019, with increased presentations of self-harm/suicidal ideation. ${ }^{19}$

The reviewed literature suggests that women are more prone to anxiety and depression, and that the mental health status of the population tends to deteriorate during large epidemics or pandemics. The current crisis requires policies that facilitate largescale behaviour change, science communication and strategies to cope with stress through psychological platforms. ${ }^{20}$ Immediate risk assessment and quick action of Vietnamese policy makers, as well as the seamless coordination between government and citizens in implementing protective measures, has resulted in low case numbers and zero deaths in the country. This has been in conjunction with media appropriately promoting public awareness about how people can protect themselves and their communities. ${ }^{21}$

This study, therefore, aimed to identify gender differences in perceived risk, anxiety levels and behavioural responses to COVID-19. This will help to develop gender-responsive policies to mitigate progression toward serious mental health conditions.

\section{Method}

\section{Study design}

This is a cross-sectional study, with the survey tool disseminated online. The first case was reported on 26 February 2020, in Pakistan. The study was conducted between 1 May 2020 and 15 May 2020, during a government-imposed lockdown. Ethical approval was obtained from the Ethical Review Committee of the Aga Khan University, Pakistan (ERC\#2020-4806-10421).

\section{Study participants}

A convenience sampling strategy was used to recruit participants. The questionnaire was launched for 2 weeks on the social media pages of a Karachi-based university hospital. Potential study participants were encouraged to share the link on their social media platforms. People aged $\geq 18$ years, residing in Pakistan for the past month, with access to the internet and willingness to participate in the study were included. Participants who could not respond to the study tool in either English or Urdu, and those who reported having filled the questionnaire at least once before, were excluded. This was an online survey tool (Google form), so no verbal or written consent could be taken in the traditional sense. Participants who met the above-stated eligibility criteria and consented to participate were able to further navigate the system. Respondents found ineligible or those not willing to consent were redirected to a thank you message, and further access to the tool was halted by the Google form.

A total of 1406 respondents completed the online questionnaire. Fifteen respondents preferred not to disclose their gender. Thus, 1391 participants were included in this study.

\section{Data collection}

Data was collected through an online self-administered structured questionnaire developed on Google Forms. Respondents were inquired about their gender, age, level of education, household income and city of permanent residence. They were asked how likely it is that they or their families might be infected with COVID-19 if no preventive measures were taken. Further questions assessed how participants perceived the severity of the symptoms caused by COVID-19, their likelihood of survival if infected and their adoption of precautionary measures. Respondents also rated the reliability of various sources of COVID-19-related information. Subsequently, the psychological impact of COVID-19 on respondents' jobs, personal life, sleep pattern and eating habits was assessed. Participants' anxiety and depression levels were assessed by the validated Hospital Anxiety and Depression Scale (HADS). This comprises 14 items (seven items on anxiety and seven items on depression) scored on a four-point Likert scale. The lowest possible scores for anxiety and depression are 0 , and the highest possible score is 15 for anxiety and 21 for depression. The scale defines a normal score as $\geq 7$, borderline abnormal score as $8-10$ and abnormal score as $\leq 11$. Higher scores imply greater severity of anxiety or depression. ${ }^{22}$

\section{Data analysis}

Data collected from respondents was stored in Google Spreadsheets, then imported to Microsoft Excel 2016 and SPSS version 21 for Windows (IBM Corporation). Data was cleaned, coded and analysed with SPSS version 21. A descriptive analysis was performed. Results were tabulated as number (percentage) for qualitative variables and mean ( \pm s.d.) for quantitative variables. Independent $t$-test, Mann-Whitney $U$-test or Pearson $\chi^{2}$-test was applied to assess the differences between women's and men's perception of susceptibility and severity toward COVID-19, anxiety, depression, the psychological impact of COVID-19, adoption of precautionary measures and reliability of information sources. Responses were classified as 'missing' if respondents left the question blank, and was excluded from the analysis. 'Don't know' was an option in survey questions that required a response on a five-point Likert scale, wherein 4 and 5 were considered as agree and strongly agree, respectively. Therefore, if the respondents replied 'Don't know', such responses were considered as a non-agreement on the scale. This type of categorisation for Likert scale-based responses is consistent with the literature. $^{23}$ Bivariate and multiple logistic regression analyses were performed to identify predictors (age, gender and household income) of anxiety and depression. Initially, a single predictor at a time was entered; crude odds ratios and 95\% confidence intervals were computed by bivariate analysis. Multivariate analysis with all predictors entered at the same time was completed to adjust for the effect of confounding, and adjusted odds ratios and 95\% confidence intervals were computed. All statistical tests were two-sided, and a $P$-value of $\leq 0.05$ was considered statistically significant and indicated in results where appropriate. Exact $P$-values are given where they are $>0.05$.

\section{Results}

A total of 1391 participant responses were included in the analysis. Table 1 shows the sociodemographic characteristics (age, education and household income) of women and men, which are comparable. The majority of the respondents were aged between 25 and 34 years (69\% of women $v .66 \%$ of men) and possessed a Bachelor's degree or above (75\% of women $v .79 \%$ of men). About $29 \%$ of women and $17 \%$ of men preferred not to disclose their household income. Around a third of women (32\%) and two-fifths of men (40\%) mentioned that their household income was below PKR 60 000. More women $(69 \%)$ than men $(40 \%)$ from Karachi participated in the survey (Table 1).

Around three-fourths of respondents perceived that they (strongly agree/agree: $71 \%$ of women $v .73 \%$ of men; $P=0.489$ ) and their family (strongly agree/agree: $74 \%$ of women $v .73 \%$ of men; $P=0.599$ ) might be infected with COVID-19 if no preventive measures were taken. However, significantly more women than men considered symptoms of COVID-19 (if infected) as severe (very severe/severe: $46 \%$ of women $v .39 \%$ of men; $P<0.05$ ). Further, $59 \%$ of women perceived themselves as likely to survive an infection, compared with $73 \%$ of men $(P<0.001)$ (Table 2). 
Table 1 Sociodemographic characteristics of the respondents by gender

\begin{tabular}{|c|c|c|c|}
\hline Characteristics & $\begin{array}{c}\text { Female, } \\
n=478, n(\%)^{\mathrm{a}}\end{array}$ & $\begin{array}{c}\text { Male, } \\
n=913, n(\%)^{\mathrm{a}}\end{array}$ & $P$-value ${ }^{b}$ \\
\hline \multicolumn{4}{|l|}{ Age, years } \\
\hline $18-24$ & $167(34.9)$ & $291(31.9)$ & \multirow[t]{8}{*}{0.833} \\
\hline $25-34$ & $163(34.1)$ & 315 (34.5) & \\
\hline $35-44$ & 89 (18.6) & $185(20.3)$ & \\
\hline $45-54$ & $32(6.7)$ & $72(7.9)$ & \\
\hline $55-64$ & $19(4.0)$ & $32(3.5)$ & \\
\hline $65-74$ & $7(1.5)$ & $16(1.8)$ & \\
\hline$\geq 75$ & 0 & $1(0.1)$ & \\
\hline Prefer not to disclose & $1(0.1)$ & $1(0.1)$ & \\
\hline \multicolumn{4}{|l|}{ Education } \\
\hline Intermediate or below & $119(24.9)$ & $188(20.6)$ & \multirow[t]{3}{*}{0.069} \\
\hline Bachelor's or above & $358(74.9)$ & $721(79.0)$ & \\
\hline Prefer not to disclose & $1(0.2)$ & $4(0.4)$ & \\
\hline \multicolumn{4}{|l|}{ Household income } \\
\hline$\leq$ PKR 20000 & $33(8.4)$ & $98(12.0)$ & \multirow[t]{8}{*}{0.877} \\
\hline PKR $20001-40000$ & $53(13.5)$ & $133(16.2)$ & \\
\hline PKR $40001-60000$ & $40(10.2)$ & $99(12.1)$ & \\
\hline PKR $60001-80000$ & $28(7.1)$ & $74(9.0)$ & \\
\hline PKR $80001-100000$ & $28(7.1)$ & $58(7.1)$ & \\
\hline PKR $100001-120000$ & $33(8.4)$ & $85(10.4)$ & \\
\hline >PKR 120000 & $63(16.0)$ & $135(16.5)$ & \\
\hline Prefer not to disclose & $115(29.3)$ & $137(16.7)$ & \\
\hline \multicolumn{4}{|l|}{ Permanent residence } \\
\hline Karachi & $329(68.8)$ & $364(39.9)$ & \multirow[t]{7}{*}{$<0.001$} \\
\hline Lahore & $36(7.5)$ & $91(10.0)$ & \\
\hline Islamabad & $25(5.2)$ & $56(6.1)$ & \\
\hline Peshawar & $8(1.7)$ & $45(4.9)$ & \\
\hline Quetta & $2(0.4)$ & $13(1.4)$ & \\
\hline Hyderabad & $18(3.8)$ & 34 (3.7) & \\
\hline Other & $60(12.6)$ & $310(34.0)$ & \\
\hline
\end{tabular}

Women were also reported to have a higher HADS anxiety score (mean \pm s.d.: $6.80 \pm 3.61$ in women $v .5 .93 \pm 3.58$ in men; $P<0.001$ ). Furthermore, the HADS depression score was high among women (mean \pm s.d.: $8.39 \pm 3.93$ in women $v .8 .01 \pm 3.69$ in men; $P=0.079$ ). More women were found to be depressed compared with men, with $58 \%$ of women and $54 \%$ of men $(P=0.244)$ scoring above the depression cut-off point $(\geq 8)$. Around three-fifths of the respondents (strongly agree/agree: $58 \%$ of women $v .61 \%$ of men; $P=$ 0.242) mentioned that COVID-19 had affected their jobs. About three-fourths of the respondents (strongly agree/agree: $73 \%$ of women $v .74 \%$ of men; $P=0.263$ ) also expressed concerns that the current pandemic is affecting their personal life. About twofourths of the respondents believed that their sleeping pattern (strongly agree/agree: $40 \%$ of women $v .39 \%$ of men; $P=0.710$ ) and eating habits (strongly agree/agree: $36 \%$ for both women and men; $P=0.726$ ) have been disturbed because of COVID-19. Significantly more men compared with women mentioned that they might start/increase cigarette consumption (strongly agree/ agree: $6 \%$ of women $v .11 \%$ of men; $P<0.001$ ), and might resort to the use of recreational drugs such as marijuana, crystallised methamphetamines, cocaine or opium products, etc. (strongly agree/agree: $4 \%$ of women $v .6 \%$ of men; $P<0.001$ ) (Table 3 ).

Significant differences were identified between women and men in adopting several precautionary measures, such as washing their hands with soap/sanitiser frequently $(100 \%$ of women $v$. $98 \%$ of men; $P<0.05$ ), wearing masks (93\% of women $v .92 \%$ of men; $P<0.05)$, covering nose and mouth when sneezing or coughing ( $98 \%$ of women $v .95 \%$ of men; $P<0.05$ ), avoiding contacting people who have a fever or respiratory symptoms ( $95 \%$ of women v. $91 \%$ of men; $P<0.05)$, avoiding going out $(87 \%$ of women $v$.

\begin{tabular}{|c|c|c|c|}
\hline Variable & $\begin{array}{c}\text { Female, } \\
n=478, n(\%)^{a}\end{array}$ & $\begin{array}{c}\text { Male, } \\
n=913, n(\%)^{a}\end{array}$ & $P$-value \\
\hline \multicolumn{4}{|c|}{ Susceptibility } \\
\hline \multicolumn{4}{|c|}{ I might contract the disease if no preventive measure is taken } \\
\hline Strongly agree & $175(36.6)$ & $336(36.8)$ & \multirow[t]{6}{*}{$0.489^{b}$} \\
\hline Agree & $166(34.7)$ & $329(36.0)$ & \\
\hline Neutral & $58(12.1)$ & $110(12.0)$ & \\
\hline Disagree & $25(5.2)$ & $44(4.8)$ & \\
\hline Strongly disagree & $54(11.3)$ & $85(9.3)$ & \\
\hline Don't know & 0 & $9(1.0)$ & \\
\hline \multicolumn{4}{|c|}{ My family might contract the disease if no preventive measure is taken } \\
\hline Strongly agree & $181(37.9)$ & $352(38.6)$ & \multirow[t]{6}{*}{$0.599^{\mathrm{b}}$} \\
\hline Agree & $172(36.0)$ & $314(34.4)$ & \\
\hline Neutral & $40(8.4)$ & $106(11.6)$ & \\
\hline Disagree & $24(5.0)$ & $46(5.0)$ & \\
\hline Strongly disagree & $60(12.6)$ & $85(9.3)$ & \\
\hline Don't know & $1(0.2)$ & $10(1.1)$ & \\
\hline \multicolumn{4}{|c|}{$\begin{array}{l}\text { I might contract COVID-19 if one of my family members tests positive for } \\
\text { the disease }\end{array}$} \\
\hline Strongly agree & $141(29.6)$ & $273(29.9)$ & \multirow[t]{6}{*}{$0.844^{\mathrm{b}}$} \\
\hline Agree & $187(39.2)$ & $333(36.5)$ & \\
\hline Neutral & $65(13.6)$ & $132(14.5)$ & \\
\hline Disagree & $25(5.2)$ & $60(6.6)$ & \\
\hline Strongly disagree & $47(9.9)$ & $84(9.2)$ & \\
\hline Don't know & $12(2.5)$ & $30(3.3)$ & \\
\hline \multicolumn{4}{|c|}{ Severity } \\
\hline \multicolumn{4}{|c|}{ Seriousness of symptoms caused by SARS-COVID19 } \\
\hline Very severe & $68(14.2)$ & $79(8.7)$ & \multirow[t]{6}{*}{$0.045^{b}$} \\
\hline Severe & 150 (31.4) & $275(30.1)$ & \\
\hline Neutral & $126(26.4)$ & $213(23.3)$ & \\
\hline Not severe & 39 (8.2) & $91(10.0)$ & \\
\hline Not severe at all & $25(5.2)$ & $48(5.3)$ & \\
\hline Don't know & $70(14.6)$ & $207(22.7)$ & \\
\hline \multicolumn{4}{|c|}{ Chance of survival if infected with COVID-19 } \\
\hline Very high & $67(14.0)$ & $238(26.1)$ & \multirow[t]{6}{*}{$<0.001^{\mathrm{b}}$} \\
\hline High & $214(44.8)$ & $427(46.8)$ & \\
\hline Neutral & $137(28.7)$ & $136(14.9)$ & \\
\hline Not high & $27(5.6)$ & $38(4.2)$ & \\
\hline Not high at all & $5(1.0)$ & $15(1.6)$ & \\
\hline Don't know & $28(5.9)$ & $59(6.5)$ & \\
\hline
\end{tabular}

$71 \%$ of men; $P<0.001$ ), avoiding crowded areas ( $96 \%$ of women v. $92 \%$ of men; $P<0.01$ ), refraining from going to a hospital or clinic (78\% of women $v .71 \%$ of men; $P<0.001$ ), avoiding going to work $(72 \%$ of women v. $57 \%$ of men; $P<0.001)$, avoiding social events (97\% of women $v .93 \%$ of men; $P<0.05)$ and avoiding domestic travel (93\% of women $v .86 \%$ of men; $P<0.001$ ) (Table 4 .).

Information about COVID-19 provided by the doctor was considered reliable by significantly more women than men (very reliable/reliable: $91 \%$ of women $v .88 \%$ of men; $P<0.05$ ). Most of the respondents (very reliable/reliable: $81 \%$ of women $v .82 \%$ of men; $P=0.507$ ) thought that the information provided through official websites, such as those run by the government, was reliable. Significantly more men than women believed that the radio (very reliable/reliable: $46 \%$ of women $v .55 \%$ of men; $P<0.05)$ and family or friends (very reliable/reliable: $46 \%$ of women $v .55 \%$ of men; $P<0.05$ ) were reliable sources for gaining information about COVID-19. Furthermore, television (very reliable/reliable: $57 \%$ of women $v$. $61 \%$ of men; $P<0.05$ ); newspapers (very reliable/reliable: $56 \%$ of women $v .58 \%$ of men; $P=0.843$ ); magazines (very reliable/ reliable: $39 \%$ of women $v$. $44 \%$ of men; $P=0.104$ ); social media, such as Facebook, WhatsApp and Instagram (very reliable/reliable: $28 \%$ of women $v .32 \%$ of men; $P=0.459$ ); and unofficial websites (very reliable/reliable: $22 \%$ of women $v .31 \%$ of men; $P<0.05)$ were 
Table 3 Psychological impact ofCOVID-19 among men and women

\begin{tabular}{|c|c|c|c|}
\hline Variable & $\begin{array}{l}\text { Female, } \\
n(\%)^{\mathrm{a}}\end{array}$ & $\begin{array}{l}\text { Male, } \\
n(\%)^{\mathrm{a}}\end{array}$ & $P$-value \\
\hline \multicolumn{4}{|c|}{ Anxiety (HADS-A score) } \\
\hline Normal $(<6)$ & $184(38.5)$ & $455(49.8)$ & \multirow[t]{2}{*}{$<0.001^{b}$} \\
\hline Abnormal $(\geq 6)$ & $294(61.5)$ & $458(50.2)$ & \\
\hline Mean ( \pm s.d.) & $6.80(3.61)$ & $5.93(3.58)$ & $<0.001$ \\
\hline \multicolumn{4}{|c|}{ Depression (HADS-D score) } \\
\hline Normal $(<8)$ & $202(42.3)$ & $417(45.7)$ & \multirow[t]{2}{*}{$0.244^{b}$} \\
\hline Abnormal ( $(8)$ & $276(57.7)$ & $496(54.3)$ & \\
\hline Mean ( \pm s.d.) & $8.39(3.93)$ & $8.01(3.69)$ & 0.079 \\
\hline \multicolumn{4}{|c|}{ COVID-19 will affect my job } \\
\hline Agree & $278(58.3)$ & $559(61.2)$ & \multirow[t]{4}{*}{$0.242^{c}$} \\
\hline Neutral & $78(16.4)$ & $149(16.3)$ & \\
\hline Disagree & $102(21.4)$ & $177(19.4)$ & \\
\hline Don't know & $19(4.0)$ & $28(3.1)$ & \\
\hline \multicolumn{4}{|c|}{ COVID-19 will affect my personal life } \\
\hline Agree & $301(63.0)$ & $581(63.6)$ & \multirow[t]{4}{*}{$0.263^{c}$} \\
\hline Neutral & 73 (15.3) & $171(18.7)$ & \\
\hline Disagree & $97(20.3)$ & $150(16.4)$ & \\
\hline Don't know & $7(1.5)$ & $11(1.2)$ & \\
\hline \multicolumn{4}{|c|}{$\begin{array}{l}\text { COVID-19 has affected my sleeping } \\
\text { pattern }\end{array}$} \\
\hline Agree & $193(40.4)$ & $352(38.6)$ & \multirow[t]{4}{*}{$0.710^{c}$} \\
\hline Neutral & $77(16.1)$ & $161(17.6)$ & \\
\hline Disagree & $190(39.7)$ & $372(40.7)$ & \\
\hline Don't know & $18(3.8)$ & $28(3.1)$ & \\
\hline \multicolumn{4}{|c|}{$\begin{array}{l}\text { COVID-19 has affected my eating } \\
\text { habits }\end{array}$} \\
\hline Agree & $170(35.6)$ & $329(36.1)$ & \multirow[t]{4}{*}{$0.726^{\mathrm{C}}$} \\
\hline Neutral & $90(18.8)$ & $158(17.3)$ & \\
\hline Disagree & $208(43.5)$ & $399(43.8)$ & \\
\hline Don't know & $10(2.1)$ & $26(2.9)$ & \\
\hline \multicolumn{4}{|c|}{$\begin{array}{l}\text { I might start smoking cigarettes/my } \\
\text { cigarette consumption might } \\
\text { increase }\end{array}$} \\
\hline Agree & $28(5.9)$ & $102(11.2)$ & \multirow[t]{4}{*}{$<0.001^{\mathrm{C}}$} \\
\hline Neutral & $23(4.8)$ & $95(10.4)$ & \\
\hline Disagree & $411(86.0)$ & 669 (73.3) & \\
\hline Don't know & $16(3.3)$ & $47(5.1)$ & \\
\hline \multicolumn{4}{|c|}{$\begin{array}{l}\text { I might start/increase the use of } \\
\text { recreational drugs (such as } \\
\text { marijuana, crystal meth, cocaine } \\
\text { or opium products, etc.) }\end{array}$} \\
\hline Agree & $21(4.4)$ & $51(5.6)$ & \multirow[t]{4}{*}{$0.001^{c}$} \\
\hline Neutral & $21(4.4)$ & $69(7.6)$ & \\
\hline Disagree & $417(87.2)$ & $747(81.8)$ & \\
\hline Don't know & $19(4.0)$ & $46(5.0)$ & \\
\hline \multicolumn{4}{|c|}{$\begin{array}{l}\text { HADS-A, Hospital Anxiety and Depression Scale - Anxiety; HADS-D, Hospital Anxiety and } \\
\text { Depression Scale - Depression. } \\
\text { a. Percentages may not total } 100 \text { because of rounding. } \\
\text { b. Pearson } \chi^{2} \text {-test. } \\
\text { c. Mann-Whitney U-test. }\end{array}$} \\
\hline
\end{tabular}

considered as reliable information sources by more men than women (Table 5).

Table 6 demonstrates the predictors of anxiety. Gender, age and household income had a significant positive association with anxiety. Women were nearly two times more likely to be anxious than men (adjusted odds ratio 1.70, 95\% CI 1.26-2.28, $P<0.001$ ). Moreover, respondents of a younger age (25-34 years) (adjusted odds ratio $2.30,95 \%$ CI $1.26-4.18, P<0.001)$ were nearly two times more likely to have anxiety than respondents over 55 years of age. Respondents with a household income between PKR 60 000 and 120000 were more likely to have anxiety than respondents with a household income of $>$ PKR 120000 (adjusted odds ratio $1.84,95 \%$ CI 1.27-2.67, $P<0.001$ ).

Table 7 shows the predictors of depression. Only household income was found to have a significantly positive association with depression in multivariate analysis. Respondents having a household income of PKR 60000-120000 were more likely to have anxiety compared with respondents who had a household income of >PKR 120000 (adjusted odds ratio 1.99, 95\% CI 1.38-2.87).

\section{Discussion}

This study assessed how gender roles in Pakistan can affect anxiety levels and behavioural responses among men and women during the COVID-19 pandemic. Both men and women were found to be anxious because of the COVID-19 pandemic. However, compared with men, more women perceived the disease to be fatal, and women were more likely to engage in preventive behaviour. These results highlight a greater need to develop gender-responsive policies in the fight to contain COVID-19.

Overall, fewer women than men responded to the questionnaire. This may be because of the male-dominated access to internet facilities in Pakistan. In Pakistan, cellular devices remain the most frequent means of accessing internet facilities, and there is a gender gap of $38 \%$ in mobile phone ownership. Indeed, several reports on internet penetration found that at least three-fourths of internet and social media users in the country are male. ${ }^{24}$

There were also significant differences in respondents' cities of permanent residence. Three-fifths of all of the female participants and two-fifths of the male participants were from Karachi. This was expected, as the survey tool was disseminated over a Karachibased university hospital's Facebook page. There are significant provincial disparities in access to internet facilities. The fewest respondents were from Balochistan, further reflecting the province's poor internet accessibility. More male (a third) respondents were from smaller cities and towns throughout the country, compared

\begin{tabular}{|c|c|c|c|}
\hline Variable & Female, $n(\%)$ & Male, $n(\%)$ & $P$-value \\
\hline \multicolumn{4}{|l|}{ Adoption of precautionary measures (frequency of yes response) ${ }^{a}$} \\
\hline Wear face masks & $444(92.9)$ & 834 (91.3) & $0.025^{\mathrm{b}}$ \\
\hline Wash hands frequently (with soap or hand sanitiser) & $476(99.6)$ & $891(97.6)$ & $0.012^{\mathrm{b}}$ \\
\hline Disinfecting floors and tables at home (with phenyl products) & $391(81.8)$ & $646(70.8)$ & $<0.001^{b}$ \\
\hline Cover nose and mouth when sneezing or coughing & $468(97.9)$ & 870 (95.3) & $0.043^{b}$ \\
\hline Avoid contacting people who have fever or respiratory symptoms & $452(94.6)$ & $832(91.1)$ & $0.040^{\mathrm{b}}$ \\
\hline Avoid contacting people who have been traveling abroad within 1 month & 441 (92.3) & $800(87.6)$ & $0.058^{\mathrm{b}}$ \\
\hline Avoid going out & $417(87.2)$ & $646(70.8)$ & $<0.001^{\mathrm{b}}$ \\
\hline Avoid crowded areas & $457(95.6)$ & $840(92.0)$ & $0.003^{\mathrm{b}}$ \\
\hline Avoid going to meat shops/market & $391(81.8)$ & $580(63.5)$ & $<0.001^{\mathrm{b}}$ \\
\hline Avoid going to hospital or clinic & $373(78.0)$ & $648(71.0)$ & $<0.001^{\mathrm{b}}$ \\
\hline Avoid going to work & $346(72.4)$ & $516(56.5)$ & $<0.001^{b}$ \\
\hline
\end{tabular}


Table 5 Perceived reliability of information sources in Pakistan, by gender

\begin{tabular}{|c|c|c|c|}
\hline Reliability of information sources & $\begin{array}{c}\text { Female, } \\
n=478 \\
n(\%)^{a}\end{array}$ & $\begin{array}{c}\text { Male, } \\
n=913 \\
n(\%)^{\mathrm{a}}\end{array}$ & $P$-value ${ }^{b}$ \\
\hline \multicolumn{4}{|l|}{ Newspaper } \\
\hline Reliable/very reliable & $248(56.0)$ & $512(58.2)$ & \multirow[t]{3}{*}{0.843} \\
\hline Neutral & $150(33.9)$ & 256 (29.2) & \\
\hline Unreliable/very unreliable & 45 (10.1) & $111(12.6)$ & \\
\hline \multicolumn{4}{|l|}{ Magazine } \\
\hline Reliable/very reliable & $173(38.5)$ & $389(44.0)$ & \multirow[t]{3}{*}{0.104} \\
\hline Neutral & $186(41.4)$ & $329(37.2)$ & \\
\hline Unreliable/very unreliable & $90(20.0)$ & $167(18.9)$ & \\
\hline \multicolumn{4}{|l|}{ Radio } \\
\hline Reliable/very reliable & $207(46.0)$ & $486(54.9)$ & \multirow{3}{*}{0.014} \\
\hline Neutral & $185(41.1)$ & $284(32.1)$ & \\
\hline Unreliable/very unreliable & 58 (12.9) & $115(13.0)$ & \\
\hline \multicolumn{4}{|l|}{ Television } \\
\hline Reliable/very reliable & $258(57.3)$ & $541(61.1)$ & \multirow[t]{3}{*}{0.401} \\
\hline Neutral & $117(26.0)$ & 206 (23.3) & \\
\hline Unreliable/very unreliable & $75(16.7)$ & $138(15.6)$ & \\
\hline \multicolumn{4}{|c|}{ Official websites such as that of the Government } \\
\hline Reliable/very reliable & 367 (81.4) & $727(82.2)$ & \multirow[t]{3}{*}{0.507} \\
\hline Neutral & $61(13.5)$ & $93(10.5)$ & \\
\hline Unreliable/very unreliable & $23(5.1)$ & $64(7.2)$ & \\
\hline \multicolumn{4}{|l|}{ Unofficial websites } \\
\hline Reliable/very reliable & $99(22.0)$ & $271(30.7)$ & \multirow[t]{3}{*}{0.013} \\
\hline Neutral & $138(30.7)$ & $256(29.0)$ & \\
\hline Unreliable/very unreliable & $212(47.3)$ & $357(40.3)$ & \\
\hline \multicolumn{4}{|c|}{ Social media platforms (WhatsApp, Facebook, Instagram) } \\
\hline Reliable/very reliable & $131(29.2)$ & $286(32.3)$ & \multirow[t]{3}{*}{0.459} \\
\hline Neutral & $130(29.0)$ & $236(26.6)$ & \\
\hline Unreliable/very unreliable & $188(41.8)$ & $364(41.1)$ & \\
\hline \multicolumn{4}{|l|}{ Your doctor } \\
\hline Reliable/very reliable & $410(91.1)$ & $775(87.6)$ & \multirow[t]{3}{*}{0.041} \\
\hline Neutral & $33(7.3)$ & $96(10.8)$ & \\
\hline Unreliable/very unreliable & $7(1.6)$ & $14(1.6)$ & \\
\hline \multicolumn{4}{|l|}{ Your family or friends } \\
\hline Reliable/very reliable & $206(46.0)$ & $471(53.3)$ & \multirow[t]{3}{*}{0.003} \\
\hline Neutral & $155(34.6)$ & $288(32.6)$ & \\
\hline Unreliable/very unreliable & 87 (19.4) & $125(14.1)$ & \\
\hline
\end{tabular}

with a tenth of female respondents. These differences can be attributable to fewer women having mobile phone ownership and social media usage in smaller towns/cities. ${ }^{24}$

Although men and women considered themselves equally susceptible to a COVID-19 infection, women were more likely to perceive the disease to be fatal and worry about their own and their family's healthcare. Apart from their professional role, women serve as primary caregivers within their family. ${ }^{25}$ Women's greater sensitivity toward familial roles and responsibilities was also reflected in a European study, which noted that pregnant women had heightened stress levels regarding the health status of their older relatives, children and unborn babies during COVID$19{ }^{26}$ Similarly, a comparison of COVID-19-related content shared on Twitter by men and women based in the USA found that women were more likely to tweet about family, social distancing and healthcare, whereas men were more likely to tweet about sports cancellations and politics. ${ }^{27}$

Men's casual attitude can be explained by gender-disaggregated data (until 24 June 2020) on COVID-19 in Pakistan, which shows that three-quarters of diagnosed cases and deaths were among men compared with a quarter among women. ${ }^{28}$ Gender-specific patterns of smoking are implicated as a significant contributor to disease severity among men. ${ }^{29}$ It was also noted that men in our study had a higher likelihood to start smoking cigarettes and using recreational drugs during the pandemic, compared with women. It is therefore not surprising that excess mortality during the pandemic was higher among men complemented by comorbid non-communicable diseases and a delay in seeking lifesaving care. $^{30,31}$

Unequal share of household responsibilities and women staying home because of school closure, lockdown and work-from-home orders may have resulted in women being more stressed. Housework is largely undocumented and unpaid. ${ }^{32}$ Working mothers spend more hours engaged in household work and child care than their husbands. One study conducted in the UK during the lockdown estimates that, on average, mothers spend 11 hours more per week on child care than fathers. Single mothers have less time to spend on child care than partnered mothers, as they are single-handedly forced to bear the brunt of the shifts in the job market. ${ }^{33}$ This additional housework could result in women permanently exiting from the labour market and add to their anxieties. These developments are concerning and emphasise the urgent need to develop labour policies that protect women in the workforce.

Despite being at lower risk of exposure to the disease and subsequently succumbing to it, women in this study were more likely to practice hygiene measures and social distancing, such as avoiding going to meat shops/markets, going out and going to work. The Gallup survey conducted during various waves of the pandemic (April 2020 to August 2021) shows that Pakistani women are more likely to stay at home as a preventive measure. ${ }^{34}$ One digital ethnographic study in Pakistan suggests that one in four men reported having attended Friday (congregational) prayers during the early phase of the pandemic in 2020. ${ }^{35}$ Although this finding might imply that men are considerably less interested in social

\begin{tabular}{|c|c|c|c|c|}
\hline Characteristics & Crude odds ratio $(95 \% \mathrm{Cl})$ & $P$-value & Adjusted odds ratio ${ }^{a}(95 \% \mathrm{Cl})$ & $P$-value \\
\hline \multicolumn{5}{|l|}{ Gender } \\
\hline Female & $1.59(1.27-1.99)$ & $<0.001$ & $1.69(1.26-2.27)$ & $<0.001$ \\
\hline Male & Reference & & Reference & \\
\hline \multicolumn{5}{|l|}{ Age, years } \\
\hline $18-24$ & $2.36(1.65-3.38)$ & $<0.001$ & $2.68(1.70-4.23)$ & $<0.001$ \\
\hline $25-34$ & $2.57(1.80-3.68)$ & $<0.001$ & $2.77(1.82-4.22)$ & $<0.001$ \\
\hline $35-44$ & $2.42(1.64-3.56)$ & $<0.001$ & $2.53(1.61-3.99)$ & $<0.001$ \\
\hline$\geq 45$ & Reference & & Reference & \\
\hline \multicolumn{5}{|l|}{ Household income } \\
\hline$\leq$ PKR 60000 & $1.69(1.20-2.36)$ & 0.002 & $1.49(1.05-2.11)$ & 0.027 \\
\hline PKR $60001-120000$ & $1.85(1.29-2.65)$ & 0.001 & $1.84(1.27-2.67)$ & 0.001 \\
\hline >PKR 120000 & Reference & & Reference & \\
\hline
\end{tabular}




\begin{tabular}{|c|c|c|c|c|}
\hline Characteristics & Crude odds ratio $(95 \% \mathrm{Cl})$ & $P$-value & Adjusted odds ratio $(95 \% \mathrm{Cl})$ & $P$-value \\
\hline \multicolumn{5}{|l|}{ Gender } \\
\hline Female & $1.15(0.92-1.44)$ & 0.224 & $1.28(0.96-1.71)$ & 0.087 \\
\hline Male & Reference & & Reference & \\
\hline \multicolumn{5}{|l|}{ Age, years } \\
\hline $18-24$ & $1.48(1.04-2.09)$ & 0.027 & $1.26(0.81-1.95)$ & 0.305 \\
\hline $25-34$ & $1.34(0.95-1.89)$ & 0.093 & $1.32(0.88-1.97)$ & 0.183 \\
\hline $35-44$ & $1.42(0.97-2.07)$ & 0.069 & $1.44(0.93-2.24)$ & 0.103 \\
\hline$\geq 45$ & Reference & & Reference & \\
\hline \multicolumn{5}{|l|}{ Household income } \\
\hline$\leq$ PKR 60000 & $1.57(1.12-2.19)$ & 0.009 & $1.53(1.09-2.17)$ & 0.015 \\
\hline PKR $60001-120000$ & $1.99(1.39-2.85)$ & $<0.001$ & $1.99(1.38-2.87)$ & $<0.001$ \\
\hline >PKR 120000 & Reference & & Reference & \\
\hline
\end{tabular}

distancing practices, men constitute a majority of waged and salaried workers in cities, and only a fifth of Pakistani women are part of the labour force. ${ }^{36}$ These differences in employment could explain why men are less likely to conform to social distancing practices than women.

Women were more likely to report that they avoid going to hospitals during the pandemic as a measure of social distancing. It may be too soon to estimate the impact of COVID-19 on maternal and child health services, but one study estimates that a modest decline of $10 \%$ in coverage of pregnancy-related and new-born healthcare in low-and middle-income countries could result in an additional 1.7 million pregnant women and 2.6 million new-borns in need of urgent medical care. ${ }^{37}$ Research conducted during the 2013-2016 Ebola outbreak in Western Africa shows how sexual and reproductive health was adversely affected by strains on healthcare systems, which often resulted in interruptions of care and redirected resources. ${ }^{38}$ A similar reduction in access can be seen during the current pandemic. Clinics operated by Marie Stopes International, which is the largest private provider of family planning services in Pakistan, reports that its activities have been reduced by up to $40 \%$ in Pakistan, as a result of the pandemic. ${ }^{39}$ Furthermore, some studies noted how the diversion of staff and funding from maternal, neonatal and child health programmes to the front line of the COVID-19 response has also decreased the quality of services available to women. ${ }^{40,41}$

Although women refrained from accessing health facilities during the pandemic, as a measure of social distancing, they still considered doctors as the most reliable source of information on COVID-19. This is consistent with findings from the Gallup survey in Pakistan. ${ }^{34}$ Hence, social media awareness campaigns and telemedicine engaging doctors can target women who tend to be more socially isolated than men during the pandemic. A study in Karachi has also commented on the need to develop psychosocial support, including essential assistance through online support groups, awareness through television or social media, and telemedicine for women. ${ }^{42}$

In this study, women showed higher levels of anxiety and depression compared with men, which suggests that they hold a greater psychiatric burden of the COVID-19 pandemic. One study conducted in China established that $54 \%$ of respondents suffered some psychological effect from the outbreak. ${ }^{43}$ This Chinese study found that women have suffered a greater psychological effect as a result of the pandemic compared with men, and may be three times more anxious than their male counterparts. Similarly, our findings corroborate with data from Turkey, where women had significantly higher scores of depression and anxiety. ${ }^{44}$ Surely this indicates that women have a higher vulnerability for developing anxiety disorders.
This is a novel study accounting for differences in perceptions of men and women, with regards to risk perceptions, anxiety levels and behavioural responses to COVID -19. However, the study had some limitations. The survey could only be accessed by the literate population in Pakistan with access to internet, so the generalisability of results needs to be viewed with caution. Moreover, in this study, most of the respondents were aged $<35$ years, which may not accurately represent the views of the older population who are at greater risk of contracting COVID-19. Nevertheless, as the majority of the population in Pakistan is $<30$ years of age, the responses are likely to represent the perceptions of the literate general population in Pakistan. Additionally, the perceptions are related to the early phase of the pandemic, and the trajectory of COVID-19-related beliefs over time is yet to be determined. However, the anxieties around COVID-19 still prevail. Indeed, the latest Gallup survey (2021) in Pakistan shows that approximately half of Pakistanis in urban areas are worried if people around them do not wear masks in public. ${ }^{34}$ Moreover, a large survey assessing anxiety and depression symptoms in the USA found that women were equally anxious at the start of the pandemic as they were in August 2021. ${ }^{45}$ Hence, the recommendations of our study to develop gender-responsive psychosocial support strategies for women, and provide additional support in their employment and child care, are needed more than ever, as we continue to battle with the pandemic.

In summary, this study assessed the gender differences in risk perceptions (susceptibility and severity of the disease), preventive behaviour (social distancing, enhanced hygiene measures) and anxiety levels during the early phase of COVID-19. The results highlight the need for gender-responsive policies in mitigating the health and economic impact of the COVID-19 pandemic. The global economy has ground to a stop, and respondents face severe economic uncertainty. Differences in type of work based on gender may result in men being unable to maintain social distancing. Furthermore, it results in women being burdened with increasing housework, which can affect their ability to engage in professional work and add to their stresses. This indicates the urgent need to develop labour laws to protect the workforce, particularly women. Furthermore, the results indicate potential avenues of disseminating gender-specific health communication. Involving doctors in healthcare communication targeting women, focusing on their need to avoid skipping hospital appointments, might prove effective. Research is required to assess strategies of reducing the frequency of in-person maternal, neonatal and child health appointments, and the potential of telemedicine for all women to remain in contact with the health system. As men are more likely to trust what they read on social media, especially if it is shared by friends or family, social media campaigns and radio programming may be effective in disseminating information, and 
the latter could be an effective tool to diverse audiences. ${ }^{46}$ This health communication should include messages about men's higher risk of dying owing to COVID-19, a lack of non-communicable disease management and smoking cessation. Most importantly, based on the discussion, policy measures must be taken to ensure the continued provision of quality healthcare to women.

Differences in type of work based on gender may result in men being unable to maintain social distancing. Furthermore, it results in women being burdened with increasing housework, which can affect their ability to engage in professional work.

Fauziah Rabbani (D), Department of Community Health Sciences and Office of Research \& Graduate Studies, Aga Khan University, Pakistan; Hyder Ali Khan Department of Community Health Sciences, Aga Khan University, Pakistan: Suneel Piryani, Department of Community Health Sciences, Aga Khan University, Pakistan; Areeba Raza Khan, Office of Research \& Graduate Studies, Aga Khan University, Pakistan; Fahad Abid, Department of Psychiatry, Jinnah Postgraduate Medical Centre, Pakistan

Correspondence: Fauziah Rabbani. Email: fauziah.rabbani@aku.edu

First received 10 Feb 2021, final revision 6 Oct 2021, accepted 8 Nov 2021

\section{Supplementary material}

Supplementary material is available online at https://doi.org/10.1192/bjo.2021.1062.

\section{Data availability}

Data and materials from the study are in the custody of Aga Khan University. Anonymised data that support the findings of this study are available from the corresponding author, F.R., upon reasonable request.

\section{Acknowledgements}

The authors would like to thank all respondents of the survey, from across Pakistan. We appreciate the support from the AKU Brain and Mind Institute (BMI) for their support and seeing this endeavour as part of their strategic framework.

\section{Author contributions}

F.R. conceived the study, guided data collection and reviewed all drafts of the manuscript. H.A.K. and A.R.K. adapted the questionnaires and wrote earlier drafts of the manuscript. S.P. analysed and narrated the data. H.A.K. edited and revised multiple drafts of the manuscript. A.R.K. assisted in posting the survey on social media channels of Aga Khan University. F.A. reviewed the online questionnaire and provided comments to include probes on resorting to recreational drugs. F.A. pre-tested the survey at his institution and provided insights to the discussion section. All authors reviewed and endorsed the final submission.

\section{Funding}

This research received no specific grant from any funding agency, commercial or not-for-profit sectors.

\section{Declaration of interest}

None.

\section{References}

1 Johns Hopkins University (JHU), Center for Systems Science and Engineering (CSSE). Coronavirus Resource Center. Johns Hopkins University, 2020 (https://coronavirus.jhu.edu/).

2 Kucharski AJ, Russell TW, Diamond C, Liu Y, Edmunds J, Funk S, et al. Early dynamics of transmission and control of COVID-19: a mathematical modelling study. Lancet Infect Dis 2020; 20: 553-8.

3 Waris A, Khan AU, Ali M, Ali A, Baset A. COVID-19 outbreak: current scenario of Pakistan. New Microbes New Infect 2020; 35: 100681.

4 Nafees M, Khan F. Pakistan's response to COVID-19 pandemic and efficacy of quarantine and partial lockdown: a review. Electron J Gen Med 2020; 17(6): em240.

5 Ministry of National Health Services Regulations and Coordinations. COVID-19 Health Advisory Platform. Government of Pakistan, 2021 (https://covid.gov.pk/).
6 Suliman S, Mkabile SG, Fincham DS, Ahmed R, Stein DJ, Seedat S. Cumulative effect of multiple trauma on symptoms of posttraumatic stress disorder, anxiety, and depression in adolescents. Compr Psychiatry 2009; 50(2): 121-7.

7 Huremović D. Psychiatry of Pandemics: A Mental Health Response to Infection Outbreak. Springer, 2019.

8 Lee AM, Wong JG, McAlonan GM, Cheung V, Cheung C, Sham PC, et al. Stress and psychological distress among SARS survivors 1 year after the outbreak. Can J Psychiatry 2007; 52(4): 233-40.

9 Mak IWC, Chu CM, Pan PC, Yiu MGC, Chan VL. Long-term psychiatric morbidities among SARS survivors. Gen Hosp Psychiatry 2009; 31(4): 318-26.

10 Wheaton MG, Abramowitz JS, Berman NC, Fabricant LE, Olatunji BO. Psychological predictors of anxiety in response to the H1N1 (swine flu) pandemic. Cogn Ther Res 2012; 36(3): 210-8.

11 Fuhrman S, Kalyanpur A, Friedman S, Tran NT. Gendered implications of the COVID-19 pandemic for policies and programmes in humanitarian settings. BMJ Glob Health 2020; 5(5): e002624.

12 Liu N, Zhang F, Wei C, Jia Y, Shang Z, Sun L, et al. Prevalence and predictors of PTSS during COVID-19 outbreak in China hardest-hit areas: gender differences matter. Psychiatry Res 2020; 287: 112921.

13 Leung GM, Ho L-M, Chan SK, Ho S-Y, Bacon-Shone J, Choy RY, et al. Longitudinal assessment of community psychobehavioral responses during and after the 2003 outbreak of severe acute respiratory syndrome in Hong Kong. Clin Infect Dis 2005; 40(12): 1713-20.

14 Rubin GJ, Amlôt R, Page L, Wessely S. Public perceptions, anxiety, and behaviour change in relation to the swine flu outbreak: cross sectional telephone survey. BMJ 2009; 339: b2651.

15 Holbrook TL, Hoyt DB, Stein MB, Sieber WJ. Gender differences in long-term posttraumatic stress disorder outcomes after major trauma: women are at higher risk of adverse outcomes than men. J Trauma Acute Care Surg 2002; 53(5): 882-8

16 Bahrami F, Yousefi N. Females are more anxious than males: a metacognitive perspective. Iran J Psychiatry Behav Sci 2011; 5(2): 83

17 MCLean CP, Anderson ER. Brave men and timid women? A review of the gender differences in fear and anxiety. Clin Psychol Rev 2009; 29(6): 496-505.

18 Rezaeian M. Age and sex suicide rates in the eastern Mediterranean region based on global burden of disease estimates for 2000. East Mediterr Health $\mathrm{J}$ 2007; 13(4): 953-60.

19 Bonello F, Zammit D, Grech A, Camilleri V, Cremona R. Effect of COVID-19 pandemic on mental health hospital admissions: comparative population-based study. BJPsych Open 2021; 7(5): e141.

20 Bavel JJV, Baicker K, Boggio PS, Capraro V, Cichocka A, Cikara M, et al. Using social and behavioural science to support COVID-19 pandemic response. Nat Hum Behav 2020; 4(5): 460-71.

21 La V-P, Pham T-H, Ho M-T, Nguyen M-H, Nguyen K-LP, Vuong T-T, et al. Policy response, social media and science journalism for the sustainability of the public health system amid the COVID-19 outbreak: the Vietnam lessons. Sustainability 2020; 12(7): 2931.

22 Herrero MJ, Blanch J, Peri JM, De Pablo J, Pintor L, Bulbena A. A validation study of the Hospital Anxiety and Depression Scale (HADS) in a Spanish population. Gen Hosp Psychiatry 2003; 25(4): 277-83.

23 Joshi A, Kale S, Chandel S, Pal DK. Likert scale: explored and explained. Br J Appl Sci Technol 2015; 7(4): 396

24 Kemp S. Digital 2020: Pakistan. DataReportal, 2020 (https://datareportal.com/ reports/digital-2020-pakistan).

25 Roy D, Tripathy S, Kar SK, Sharma N, Verma SK, Kaushal V. Study of knowledge, attitude, anxiety \& perceived mental healthcare need in Indian population during COVID-19 pandemic. Asian J Psychiatry 2020; 51: 102083.

26 Corbett GA, Milne SJ, Hehir MP, Lindow SW, O'Connell MP. Health anxiety and behavioural changes of pregnant women during the COVID-19 pandemic. Eur J Obstet Gynecol Reprod Biol 2020; 249: 96.

27 Thelwall M, Thelwall S. Covid-19 tweeting in English: gender differences. Profesional De La Información 2020; 29(3).

28 The COVID-19 Sex-Disaggregated Data Tracker | Global Health 50/50, 2020 (https://globalhealth5050.org/the-sex-gender-and-covid-19-project/the-datatracker/)

29 Cai H. Sex difference and smoking predisposition in patients with COVID-19. Lancet Respir Med 2020; 8(4): e20.

30 Lai AG, Pasea L, Banerjee A, Hall G, Denaxas S, Chang WH, et al. Estimated impact of the COVID-19 pandemic on cancer services and excess 1-year mortality in people with cancer and multimorbidity: near real-time data on cancer care, cancer deaths and a population-based cohort study. BMJ Open 2020; 10(11): e043828.

31 CDC COVID-19 Response Team et al. Preliminary estimates of the prevalence of selected underlying health conditions among patients with coronavirus 
disease 2019—United States, February 12-March 28, 2020. Morb Mortal Wkly Rep 2020; 69(13): 382.

32 McLaren HJ, Wong KR, Nguyen KN, Mahamadachchi KND, Covid-19 and women's triple burden: vignettes from Sri Lanka, Malaysia, Vietnam and Australia. Soc Sci 2020; 9(5): 87.

33 Zhou M, Hertog E, Kolpashnikova K, Kan M-Y. Gender inequalities: changes in income, time use and well-being before and during the UK COVID-19 lockdown. SocArXiv [Preprint] 2020. Available from: https://doi.org/10.31235/osf.io/u8ytc

34 Gallup Pakistan. Coronavirus Attitude Tracker Survey Pakistan: Wave 10 Results. Gallup Pakistan, 2021 (https://gallup.com.pk/wp/wp-content/uploads/2021/06/ Gallup-Covid-Opinion-Tracker-Wave-10.pdf).

35 Ghadyani M, Hussain H, Odeh W, Wood P. Responses to the COVID-19 Pandemic in Syria, Iran and Pakistan. Aga Khan University, 2020 (https://ecommons.aku. edu/cgi/viewcontent.cgi?article=1001\&context=uk_ismc_series_ops).

36 Pakistan Bureau of Statistics. Pakistan Employment Trends. Pakistan Bureau of Statistics, 2018 (https://www.pbs.gov.pk/content/pakistan-employment-trends2018).

37 Riley T, Sully E, Ahmed Z, Biddlecom A. Estimates of the potential impact of the COVID-19 pandemic on sexual and reproductive health in low-and middleincome countries. Int Perspect Sex Reprod Health 2020; 46: 73-6.

38 Menéndez $C$, Lucas A, Munguambe $K$, Langer A. Ebola crisis: the unequal impact on women and children's health. Lancet Glob Health 2015; 3(3): e130.

39 Hussain AT. Lost Protection. The News on Sunday, 2020 (https://www.thenews.com.pk/tns/detail/652596-lost-protection).

40 de Paz C, Muller M, Munoz Boudet AM, Gaddis I. Gender Dimensions of the COVID-19 Pandemic. World Bank, 2020 (https://openknowledge.worldbank.org/ bitstream/handle/10986/33622/Gender-Dimensions-of-the-COVID-19-Pandemic. pdf? sequence=1\&isAllowed=y).

41 Wenham C, Smith J, Morgan R. COVID-19: the gendered impacts of the outbreak. Lancet 2020; 395(10227): 846-8.

42 Asim SS, Ghani S, Ahmed M, Asim A, Qureshi AFK. Assessing mental health of women living in Karachi during the Covid-19 pandemic. Front Glob Womens Health 2021; 1: 24

43 Wang Y, Di Y, Ye J, Wei W. Study on the public psychological states and its related factors during the outbreak of coronavirus disease 2019 (COVID-19) in some regions of China. Psychol Health Med 2021; 26(1): 13-22.

44 Özdin S, Bayrak Özdin S.. Levels and predictors of anxiety, depression and health anxiety during COVID-19 pandemic in Turkish society: the importance of gender. Int J Soc Psychiatry 2020; 66(5): 504-11.

45 National Center for Health Statistics. Anxiety and Depression: Household Pulse Survey. Centers for Disease Control and Prevention, 2021 (https://www.cdc. gov/nchs/covid19/pulse/mental-health.htm).

46 Abrams EM, Greenhawt M. Risk communication during COVID-19. J Allergy Clin Immunol Pract 2020; 8(6): 1791-4. 